\title{
Rural Residents' Perception about the Coverage, Cost and Access of Ambulance Services
}

\author{
Alana Prosser, Jessica Prosser, Denese Playford PhD \\ Affiliation: \\ The Rural Clinical School of Western Australia, The University of Western Australia, Crawley, Western Australia, \\ Australia
}

\section{ABSTRACT \\ Background}

While there are numerous studies investigating use and outcomes of the ambulance service, there are none looking at population attitudes and knowledge about the ambulance service. The aim of this study was to see if education is required for a sample population representative of rural Australia in regards to cost and coverage.

\section{Methods}

This study used a knowledge, attitude and practice survey voluntarily self-completed by a sample population recruited opportunistically from a number of health and public areas in the city of Geraldton, including the Emergency Department, a General Practise Clinic, a Physiotherapy Clinic and a Shopping Centre.

\section{Results}

229 surveys were completed and showed that $30.1 \%$ of the sample population had no coverage in that they were not a pensioner, had no private health insurance and did not posses St John country cover. Aboriginal people were more likely than non-Aboriginal people to be without cover. Although $96 \%$ of people believed that everyone should be covered, $56 \%$ of participants did not know who administers rural ambulance coverage and $59 \%$ did not know the average call out fee for a life threatening call. The majority did not consider costs when using an ambulance.

\section{Conclusion}

The results demonstrated considerable lack of knowledge about ambulance cover and suggested that public education about ambulance services would be beneficial.

\section{Keywords}

rural, ambulance service, population survey

Corresponding Author: Denese Playford, denese.playford@uwa.edu.au

\section{INTRODUCTION}

St John Ambulance in Western Australia covers 2 million square kilometres making it the largest area covered by any single ambulance service in Australia.(1) In country Western Australia, St John Ambulance services cater for over 32,000 people each year and for those individuals who do not possess the appropriate cover they can be out of pocket in excess of $\$ 800$.(1)

St John Ambulance Service in Western Australia are a user-pays organisation; so transportation in an ambulance is not free.(2) Contrary to many people's perception, Medicare does not cover ambulance usage.(2) In metropolitan areas of Western Australia, Health Benefits Fund owns and operates St John Ambulance whereas in country Western Australia St John Ambulance is run by local St John sub-centres.(3) To be covered in Western Australia an individual may join a private health insurance fund or alternatively obtain country health cover if residing in a rural town.(3) Furthermore pensioners are entitled to 
free ambulance services and senior citizens over 65 receive a $50 \%$ subsidy.(4)

The Australian Heart Foundation in 2008 found that $6.7 \%$ of people aged between 35 and 65 years of age stated that they were very or somewhat likely to delay calling an ambulance due to the cost involved.(2) In conjugation research conducted in Perth, Western Australia showed that people who had insurance were more likely to call an ambulance when experiencing chest pain than those without insurance.(5) Thus cost may act as a disincentive to accessing ambulance. However these two studies were conducted in urban areas and can't be extrapolated for a rural population due to the differences in the coverage systems highlighted above.

Analysis of rural ambulance usage data in New South Wales showed that rural residents were significantly less likely to call an ambulance than urban residents, even for triage category 1 and 2 emergencies.(6) This suggests that rural populations may think differently about ambulance services, and need to be separately studied.

Further factors additional to cost may be involved in reduced access to ambulance services. One study in South America found a concerning number of people were not aware of the emergency call out number for ambulance attendance.(7) There are no equivalent Australian studies looking at public knowledge about Ambulance services, or how many Australians have ambulance cover.

This study determined the proportion of people of all age brackets without cover in the rural community of Geraldton. It investigated whether cost was considered when requiring an ambulance and thereby delaying treatment. The aim of this study is to see if education is required for the sample population in regards to cost and coverage, with the hypothesis, based on the South American study, that there is a lack of knowledge about cost and coverage of ambulance services and a concomitant need for the Geraldton population, representing rural populations at large, to be educated in regards to ambulance coverage.

\section{METHODS}

\section{Study Design}

This cross-sectional observational study used a brief unpiloted survey to assess knowledge, attitude and practice of a selection of the population likely to use ambulance services.

\section{Setting}

The sample population was recruited opportunistically from a number of health and public areas in the city of Geraldton inclusive of the ED of the Geraldton Regional Hospital, Geraldton Physiotherapy Clinic, Panaceum General Practice Clinic and Centro Shopping Centre in Geraldton.

\section{Participants}

A sample size of 265 was aimed for, using a confidence interval of 6 , a confidence level of $95 \%$ and Geraldton's population size of 37,000 . Participants were required to give voluntary informed consent and be over the age of 18 .

\section{Instrumentation}

The unpiloted survey consisted of 5 sections. The first section was general patient information, this asked basic demographic questions inclusive of age, gender, first language, place of residence and ethnicity. The second section was related to whether the participants had entitlement cards (pension or health care) or had ambulance cover (private health or St John Country ambulance cover). The third section was related to their knowledge on ambulance cover; this section consisted of two multiple-choice questions. The fourth section surveyed their use of the ambulance services and any barriers they encountered. Lastly the fifth section involved 5 statements asking the participant to agree or disagree with each comment relating to the ambulance services. The survey is provided in Appendix 1.

\section{Analysis}

The dependent variables for this study were knowledge about ambulance coverage and cost, perception about the ambulance services and the percentage of people who are covered in the sample population. The independent variables were age, residence and ethnicity.

The data was maintained in excel and analysed in SPSS. The dependent variables were graphed, and tabulated.

\section{Ethics Approval}

The research project was approved by the University of Western Australia Human Research Ethics Committee and the Western Australia Country Health Services (WACHS) Research Ethics Committee. Public liability approval was also obtained from the Centro Geraldton shopping centre to enable surveys to be distributed to the public. 


\section{RESULTS}

The 229 completed surveys were obtained from all the collection points: $43,81,15$ and 90 from the Emergency Department, the General Practise Clinic, the Physiotherapy Clinic and Centro Shopping Centre respectively. This represented $86 \%$ attainment of the proposed sample size.

\section{Demographic Results}

As seen in table 1 the greatest number of surveys completed was by the age bracket of 41-60 years old. Relative to Geraldton as a whole, this represents a sample biased towards older age groups, and towards women, but with a good representation for Aboriginal people. There was no association of age with sex, Aboriginality or place of residence. The data illustrates a higher proportion of Aboriginal people in younger age groups were surveyed, as fits with the younger Aboriginal population in Geraldton. Over $80 \%$ of all surveys from each age bracket were completed by those living in Geraldton.

\begin{tabular}{lllllrr} 
Age & $\begin{array}{l}\text { Number } \\
(\mathbf{2 2 9})\end{array}$ & $\begin{array}{c}\% \\
\text { male }\end{array}$ & $\begin{array}{c}\text { \% } \\
\text { female }\end{array}$ & $\begin{array}{c}\text { Total } \\
\text { Aboriginal }\end{array}$ & $\begin{array}{r}\text { \% lives in } \\
\text { Geraldton }\end{array}$ \\
\hline $18-25$ & 47 & 42.6 & 57.4 & 100 & 10.6 & 83.0 \\
$26-40$ & 53 & 37.7 & 62.3 & 100 & 3.8 & 81.1 \\
$41-60$ & 76 & 50.0 & 50.0 & 100 & 14.5 & 80.3 \\
$61-80$ & 44 & 50.0 & 50.0 & 100 & 2.3 & 86.4 \\
$>80$ & 9 & 44.4 & 55.6 & 100 & 0 & 88.9 \\
\hline
\end{tabular}

Table 1: Number of Surveys collected and demographic proportions in relation to age

\section{Cover}

\begin{tabular}{lc}
\multicolumn{1}{c}{ Type of Cover } & \% of participants \\
\hline Pension Card & 15.7 \\
Private Health Cover & 52.8 \\
St John Country Cover & 27.5 \\
No Cover & 30.1 \\
\hline Table 2: Coverage
\end{tabular}

Table 2 illustrates that $30.1 \%$ of the sampled Geraldton population have no coverage: they are not a pensioner, have no private health insurance and do not posses St John country cover.

\begin{tabular}{lll} 
Place of Residence & $\begin{array}{l}\text { \% of } \\
\text { participant } \\
\text { s covered }\end{array}$ & $\begin{array}{l}\text { \% of } \\
\text { participant } \\
\text { s not } \\
\text { covered }\end{array}$ \\
\hline Geraldton & 87.8 & 12.2 \\
Not Geraldton & 97.5 & 2.5 \\
\hline Table 3: Place of residence and coverage &
\end{tabular}

Table 3 shows that a higher proportion of people living in Geraldton did not have any cover $(p=0.05)$.

\begin{tabular}{lll} 
Ethnicity & \% covered & $\%$ not covered \\
\hline ATSI & 63.2 & 36.8 \\
Non-ATSI & 91.9 & 8.1 \\
\hline Table 4: Ethnicity (Aboriginal or Torres Strait Islander) and \\
coverage
\end{tabular}

Table 4 shows a significantly higher proportion of Aboriginal respondents did not have cover $(p=0.001)$ than Non-Aboriginal respondents.

\section{Knowledge}

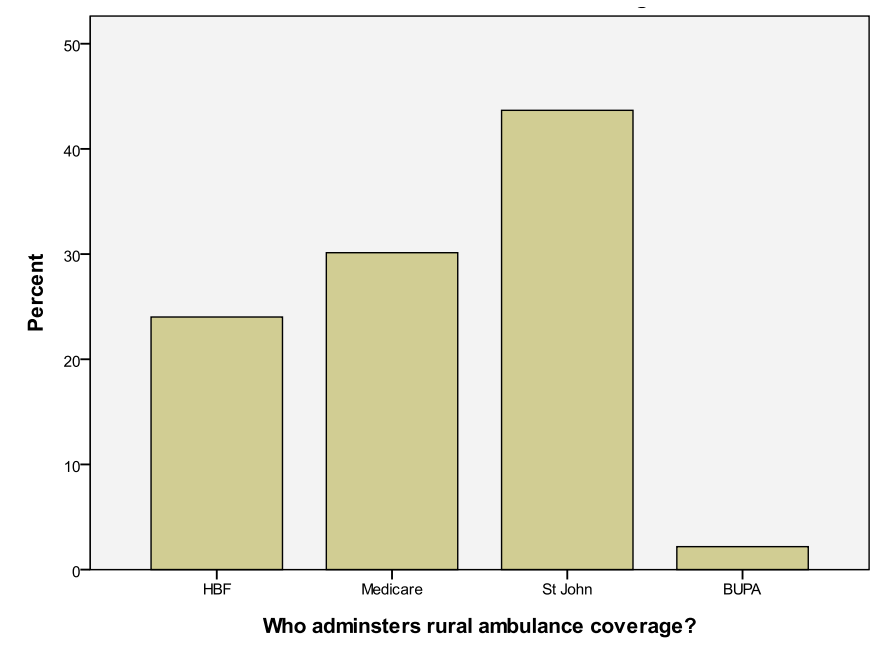

Figure 1: Knowledge question 1

St John administers rural ambulance cover. This was a question asked in the knowledge section of the survey. The results showed that $56 \%$ of people answered incorrectly. Specifically $24 \%$, $30 \%$ and $2 \%$ believed that $\mathrm{HBF}$, Medicare and BUPA respectively was the correct answer. 


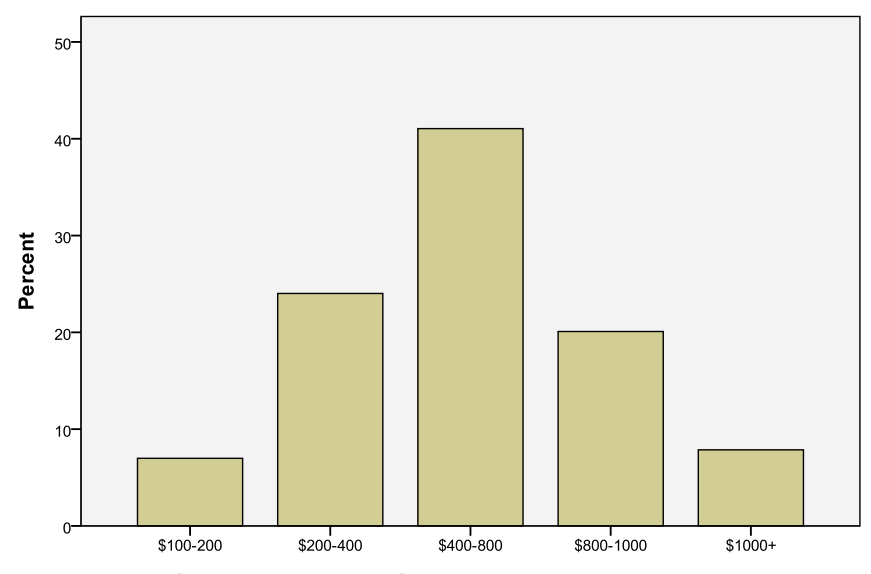

For a life threatening call out for an ambulance service approximately how much do you think it will cost?
The call-out cost for a life-threatening ambulance trip was $\$ 779$ when this survey was completed by our participants. Of our participants $59 \%$ answered this incorrectly.

Figure 2: Knowledge question 2

\section{Cost}

\begin{tabular}{llll} 
Age (years) & $\begin{array}{c}\% \text { of those who have } \\
\text { used an ambulance }\end{array}$ & $\begin{array}{c}\% \text { that considered the } \\
\text { cost }\end{array}$ & $\%$ who were covered \\
\hline $18-25$ & 19.1 & 0 & 77.8 \\
$26-40$ & 28.3 & 13.3 & 80.0 \\
$41-60$ & 38.2 & 20.7 & 86.2 \\
$61-80$ & 27.3 & 16.7 & 75.0 \\
$80+$ & 33.3 & 33.3 & 66.7 \\
\hline
\end{tabular}

Table 5: Percentage of those who have used an ambulance and whether they considered the cost and if they were covered in relation to their age

Participants between the age of 41 and 60 years of age had the highest ambulance usage. A small proportion of participants considered the cost before calling an ambulance and a high percentage of participants were covered, however $20 \%$ of participants were not covered and were subject to paying $\$ 779$.

Figure 3 shows that a large proportion of participants have never required an ambulance, however there is $16 \%$ that avoided using an ambulance due to the knowledge of cost.

Ninety six percent of people believed that everyone should be covered.

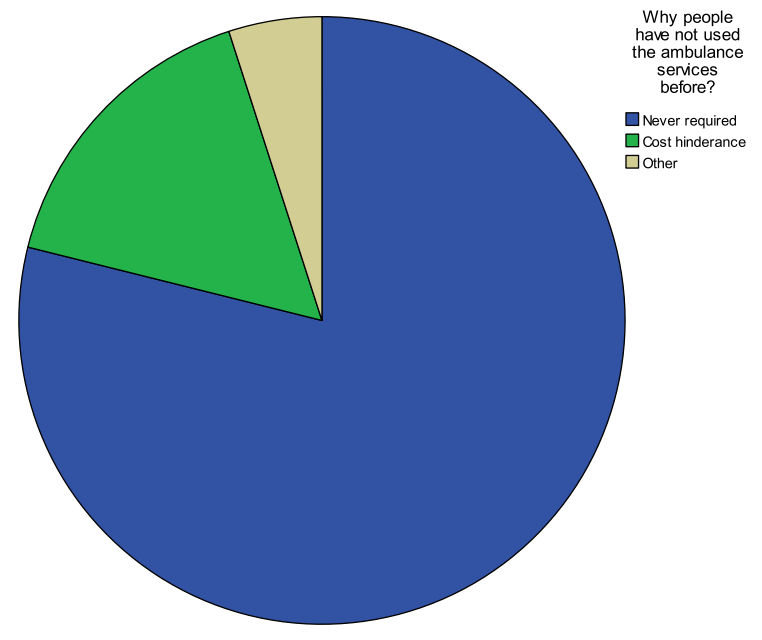

Figure 3: Why some participants have never used the ambulance service before? 


\section{General Information about the Ambulance Service}

\begin{tabular}{llllll} 
Question & $\begin{array}{l}\text { Strongly } \\
\text { Agree }\end{array}$ & Agree & Neutral & Disagree & $\begin{array}{l}\text { Strongly } \\
\text { Disagree }\end{array}$ \\
\hline "I would hesitate to ring an ambulance if it is likely to & 38 & 54 & 36 & 55 & 46 \\
cost hundreds of dollars" & $16.6 \%$ & $23.6 \%$ & $15.7 \%$ & $24.0 \%$ & $20.1 \%$ \\
"The ambulance service should be a professional & 47 & 72 & 51 & 46 & 13 \\
service and not staffed by volunteers" & $20.5 \%$ & $31.4 \%$ & $22.3 \%$ & $20.1 \%$ & $5.7 \%$ \\
"The ambulance service in the country does a lot & 62 & 127 & 36 & 3 & 1 \\
more than just responding to emergencies" & $27.1 \%$ & $55.5 \%$ & $15.7 \%$ & $1.3 \%$ & $0.4 \%$ \\
"The general population need to understand more & 91 & 112 & 23 & 3 & 0 \\
about how rural ambulance services operate" & $39.7 \%$ & $48.9 \%$ & $10.1 \%$ & $1.3 \%$ & $0 \%$
\end{tabular}

Table 6: Attitude questions - Number of participants who agree or disagree with the following statements

Over $50 \%$ of the respondents felt that the ambulance service should be professional and over $80 \%$ knew the service was more than just an emergency response. Nearly $90 \%$ felt that more education about the ambulance service was required in Geraldton.

\section{DISCUSSION}

This study demonstrated considerable lack of knowledge about ambulance cover in a rural town and suggests that public education about ambulance coverage would be beneficial. This was in concurrence with our hypothesis and was demonstrated participants' response to two basic knowledge questions, which showed that $56 \%$ of participants did not know who administers rural ambulance coverage and $59 \%$ did not know the cost of a call out fee for a life-threatening call. Of participants who answered at least one knowledge question incorrectly $53 \%$ had no cover. This therefore indicates that lack of knowledge about coverage may relate to lack of cover. Therefore informing the population about the high cost of ambulance services and cover options may encourage people to obtain cover. There have been no studies in Australia or internationally for comparison of these data.

Nearly one third (30.1\%) of participants had no cover when it came to ambulance services. This is despite the fact that St John's Country cover for ambulance service is readily available in rural areas and is a relatively cheap alternative compared to private health insurance.(8) In 2012, St John Country cover could be obtained for a flat fee of $\$ 55$ per year for a single person or $\$ 95$ for a family per year.(9) In comparison HBF a means of private insurance offers a fee of $\$ 96.20$ per year for a single person for ambulance cover only.(10) Of the participants with cover, $52.8 \%$ had private health insurance, suggesting that many are not aware of the cheaper alternative. These facts could be readily conveyed through simple public education.

There is a little literature showing that public education is effective in increasing public awareness of ambulance services and reducing population-level morbidity. By the conclusion of one public campaign about pre-hospital care in Germany, which placed "stroke is an emergency" posters in local buses and repeated this message in a series of newspaper articles, the median time to hospital for stroke decreased from 12 hours to 3.2 hours, increasing successful thrombolysis.(11) A systematic review of 11 papers found that education through public media was weakly associated with timely ambulance call-out, and moderately associated with calls to Triage Centres and Emergency Department presentations for chest pain.(12) This preliminary evidence suggests that public education may result in better outcomes.

Inferential statistics in this study showed a relationship between ambulance coverage, rural location and ethnicity. Of the participants who had no cover, more people whose usual residence was Geraldton than those who lived elsewhere, had no cover. This could be concerning if Geraldton is representative of other regional towns. This study also showed a significantly higher proportion of Aboriginal participants did not have cover. These data are consistent with socioeconomic influences on health cover. Results from a whole population study in Utah showed that persons of a lower socio-economic status were less likely to have health insurance and more likely to delay emergency health care.(13)

Our study showed that a substantial $16 \%$ of participants who have required an ambulance considered the cost. Other studies have similarly showed that cost is a factor in delaying usage of emergency services. In 2008 the Heart Foundation found that $6.7 \%$ of respondents would delay calling an ambulance because it is too expensive.(2) When extrapolating this result to 
the total Australian population, over 650,000 people would delay calling an ambulance because of cost consideration when experiencing heart attack warning signs.(2) This positive relationship between cost and delaying emergency services is consistent internationally.(14)

Of the $6.7 \%$ that would delay calling an ambulance found in the Heart Foundation study, the majority were from the Northern Territory and Western Australia.(2) Queensland had the lowest rate of patients delaying because of cost, which is likely due to the introduction of universal cover in Queensland in 2003.(2) Currently ambulance services in Australia are provided by the state government except in the Northern Territory and Western Australia. Our results showed that $96 \%$ of participants believed that everyone should be covered. There has been consideration given into whether Western Australia should adopt a similar system to Queensland where ambulance levy was initially collected in electricity bills, until June 2011 when Queensland introduced a fully subsidised coverage system paid by the Government.(15) This means the public have assurance of coverage in times of emergencies. However Western Australia is a large state with a widely dispersed population, making it difficult for a government system to ensure services in all rural areas.(1)

The population's perception about rural ambulance services included a sense that ambulance service should be run by professionals rather than by volunteers. A possible reason could be that professionals are perceived as more accredited and having higher knowledge than volunteers.(16) Although this may hold true, volunteers are needed in a rural setting to assure the ambulance system still runs.(1) This is because volunteer sub-centres ensure there are ambulance services in each town, as one in five Western Australians required ambulance transport outside city areas in 2009. If there was a full paramedic model in rural areas only larger towns would be included.(1)

Unexpectedly, the population showed awareness of the general nature of ambulance service, correctly understanding that "The ambulance service in the country does a lot more than just responding to emergencies", since in 2005-2006, $32.9 \%$ of ambulance call outs were for nonemergencies.(17) Despite this correct answer, nearly $90 \%$ of participants went on to agree that more education is required about the rural ambulance services.

\section{CONCLUSION}

In conclusion, there was a lack of knowledge about the ambulance coverage system from the
Geraldton population, representing an Australian regional rural town. These data suggest need for public education on ambulance coverage. Since over 100,000 West Australians place an ambulance call every year, population level education could encourage a substantial number of people to obtain appropriate cover and receive adequate ambulance care when needed.

\section{CONFLICT OF INTEREST}

The authors declare they have no conflict of interest.

\section{ACKNOWLEDGEMENTS}

Thanks to Professor Sandra Thompson at The Combined Universities Centre For Rural Health, who facilitated this study.

\section{REFERENCES}

1. St John Ambulance Western Australia. Country Ambulance Cover. [Jan 27, 2011]; Available from: http://www.ambulance.net.au/content.asp?id= 114.

2. Consumers Health Forum of Australia. Submission on the Heart Foundation's Universal Ambulance Cover Discussion Paper. 2010; Available from: https://http://www.chf.org.au/pdfs/sub/sub625-ambulancecover-jul10.pdf.

3. St John Ambulance Western Australia. Ambulance Services 2000. 2010; Available from:

http://www.ambulance.net.au/content.asp?id= 166 - ambulancecover.

4. Government of Western Australia Department of Health. Ambulance Services for Seniors 2006. 2010; Available from:

http://www.ambulancepolicy.health.wa.gov.au /questions/index.cfm.

5. Ingarfield SL JI, Jelinek GA, Mountain D. Patient delay and use of ambulance by patients with chest pain. Emergency Medicine Australia. 2005;17:218-23.

6. Reed B. Ambulance utilisation in serious health emergencies in rural populations: measuring unmet need. : Ambulance Research Institute. 2011.

7. Baez AA, Giraldez E, Lane PL, Pozner C, Rodriguez J, Rogers S. Knowledge and attitudes of the out-of-hospital emergency care consumers in Santo Domingo, Dominican Republic. Prehospital and disaster medicine. 2008 2008;23(4):373-6. 
8. St John Ambulance Western Australia. A brief history of St John Ambulance 2000. Available from:

http://www.ambulance.net.au/content.asp?id= 111.

9. St John Ambulance. Country Ambulance Cover. 2011; Available from:

newmansja.com.au/Ambulance-MembershipFund.php.

10. HBF. Taking out Urgent Ambulance cover. 2012; Available from: http://www.hbf.com.au/ambulance.

11. Schmidt NK, Huwel J, Weisner B. Causes of a prolonged prehospital phase in patients admitted to a stroke unit. Can it be influenced by campaigns to educate the public? Nervenarzt. 2005 Feb;76(2):181-5.

12. Kainth A, Hewitt, A., Pattenden, J., Sowden, A., Duffy,S., Watt, I., Thompson, D., \& Lewin, R. Systematic review of interventions to reduce delay in patients with suspected heart attack. Emergency Medicine Journal. 2004;21(4):506-8.

13. Surunda A BT, Knight S, Dean J. 2005 [cited 2012 Jul 30 ];5(29). Health insurance, neighbourhood income and emergency department usage by Utah children. BMC Health Services Research. 2005;5(1):29-34.

14. Jacob S JJ, Heller M, Stoltzfus J. Patient and Physician Perspectives on Ambulance Utilization Prehospital Emergency Care. 2008;12(2):176-81.

15. Queesnland Government Queensland Ambulance Service. [cited 201310 September, ]; Available from: https://ambulance.qld.gov.au/subscribe/faq.as p.

16. O'Meara P TV, Stirling C, Walker J, .

Extending the paramedic role in rural Australia; story of flexibilty and innovation. Rural and Remote Health. 2012;12 (Online).

17. Queensland Government. Queensland Ambulance Service Audit Report. 2007; Available from: http://www.emergency.qld.gov.au/publications /pdf/finalreport.pdf.

18. Kerr D HD, Smith J, Bunker S. Predictors of ambulance use in patients with acute myocardial infarction in Australia. Emergency Medicine Journal. 2006;23:948-52. 
All the information you provide in this questionnaire is strictly confidential.

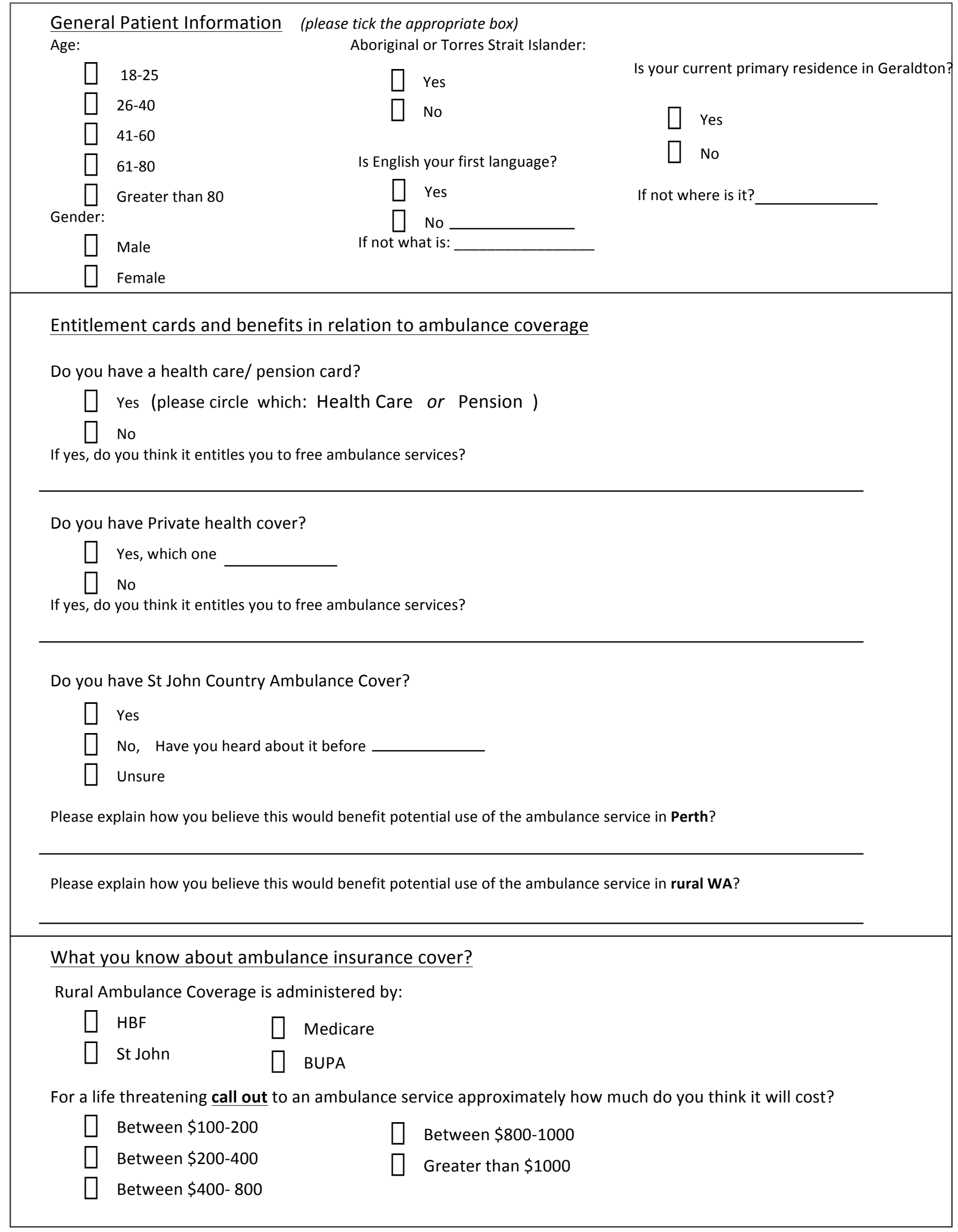


Your use of the ambulance service

Have you used/required/travelled as a patient in an ambulance before?
$\square$ Yes
$\square$ No

If yes, was it in a rural location?
$\square$ Yes
$\square$ No

Did you consider the cost before using the ambulance service?

$\square$ Yes

$\square$ No

Were you covered for the costs associated with this trip?

$\square$ Yes

$\square$ No

Were there any barriers making you reluctant to use the ambulance service?

If you have never used an ambulance service before is it because:

$\square$ You never required an ambulance

$\square$ The knowledge of the cost stopped you from calling an ambulance

$\square$ Other:

Do you think everyone should be covered for ambulance services?

$\square$ Yes

$\square$ No

Would you like to know more about ambulance cover?

$\square$ Yes

D No

How much do you agree with these statements?

"In rural areas, ambulance response times (getting to an emergency) are said to be too slow"
$\square$ Strongly Agree
$\square$ Agree
$\square$ Neutral
$\square$ Disagree
Strongly Disagree

"I would hesitate to ring an ambulance if it is likely to cost hundreds of dollars"
$\square$ Strongly Agree
Agree
$\square$ Neutral
$\square$ Disagree
Strongly Disagree

"The ambulance service should be a professional service and not staffed by volunteers"
$\square$ Strongly Agree
Agree
$\square$ Neutral
$\square$ Disagree
Strongly Disagree

"The ambulance service in the country does a lot more than just responding to emergencies"
$\square$ Strongly Agree
$\square$ Agree
$\square$ Neutral
$\square$ Disagree
Strongly Disagree

"The general population need to understand more about how rural ambulance services operate"
$\square$ Strongly Agree
Agree
Neutral
Disagree
Strongly Disagree 